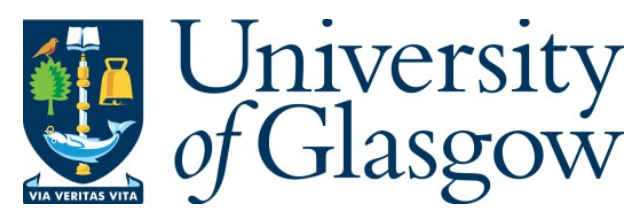

Bhattacharyya, S., Mittal, T., Abayalingam, M., Kabir, T., Dalby, M., Cleland, J. G.F., Baltabaeva, A., and Rahman Haley, S. (2016) Classification of aortic stenosis by flow and gradient patterns provides insights into the pathophysiology of disease. Angiology, 67(7), pp. 664-669.

There may be differences between this version and the published version. You are advised to consult the publisher's version if you wish to cite from it.

http://eprints.gla.ac.uk/128388/

Deposited on: 1 November 2016

Enlighten - Research publications by members of the University of Glasgow http://eprints.gla.ac.uk 


\section{Classification of Aortic Stenosis By Flow and Gradient Patterns Provides Insights into the Pathophysiology of Disease}

Sanjeev Bhattacharyya MD MRCP ${ }^{1,2}$, Tarun Mittal MD FRCR ${ }^{3}$, Mayavan Abayalingam MBBS $^{1}$, Tito Kabir MD MRCP ${ }^{1}$, Miles Dalby MD MRCP FESC ${ }^{1}$, John G Cleland MD $^{1}$, Aigul Baltabaeva MD PhD FESC ${ }^{1,2}$, Shelley Rahman Haley MD FRCP ${ }^{1,2}$

${ }^{1}$ Department of Cardiology, Harefield Hospital, London, United Kingdom

${ }^{2}$ Echocardiography Laboratory, Harefield Hospital, London, United Kingdom

${ }^{3}$ Department of Imaging, Harefield Hospital, London, United Kingdom

Word Count: 3397

Key Words: Aortic Stenosis; Valve Calcification; Echocardiography; Cardiac Computed Tomography

\section{Address for Correspondence:}

Dr Sanjeev Bhattacharyya MD, MRCP, FESC

Department of Cardiology \& Echocardiography Laboratory

Harefield Hospital, UK

UB9 6JH, UK

Telephone: 01895828586 Fax: 01895828587

E-mail: sanjeev144@hotmail.com

List of co-author e-mails: t.mittal@rbht.nhs.uk, mayavan@doctors.org.uk, t.kabir@rbht.nhs.uk, m.dalby@rbht.nhs.uk, j.cleland@rbht.nhs.uk, a.baltabaeva@rbht.nhs.uk, s.rahmanhaley@rbht.nhs.uk 


\section{ABSTRACT}

Different patterns of flow and valve gradients can lead to diagnostic uncertainty about the severity of aortic stenosis (AS). Consecutive patients with severe AS (valve area $<1$ $\mathrm{cm}^{2}$ ) underwent echocardiography and computed tomography. Patients were classified into four groups (high gradient/normal flow $\left(\mathrm{HG}_{\mathrm{NF}}\right)$, high gradient/low flow $\left(\mathrm{HG}_{\mathrm{LF}}\right)$, low gradient/normal flow ( $\left(G_{N F}\right)$ and low gradient/low flow $\left(L G_{L F}\right)$ ). Low flow was defined as stroke volume index $<35 \mathrm{ml} / \mathrm{m}^{2}$ and low gradient as a mean aortic gradient $<40 \mathrm{mmHg}$. Aortic valve calcification (AVC) was calculated using the Agatston score. Of 181 patients, 56, 30, 46 and 49 had $H G_{N F}, H G_{L F}, L_{N F}$ and $L G_{L F}$ with median AVC of 2048, 2015,1366 and $1178 \mathrm{AU} / \mathrm{m}^{2}(\mathrm{p}<0.0001)$ and valvulo-arterial impedance of $4.5,6.4,4.2$ and 5.9 respectively $(p<0.001)$. Amongst those with $L_{\mathrm{LF}}, \mathrm{AVC}$ was lower in patients with preserved compared to reduced left ventricular ejection fraction (1018 versus 2550 $\left.\mathrm{AU} / \mathrm{m}^{2} ; \mathrm{p}<0.0001\right)$ but valvulo-arterial impedance was similar $(\mathrm{p}=0.33)$. LG $\mathrm{LF}_{\mathrm{LS}}$ with preserved ejection fraction is associated with lower AVC and may identify patients with less severe AS in association with an adaptive ventricular response to high afterload. 


\section{INTRODUCTION}

Calcific aortic stenosis is common (1) and the adverse prognosis of symptomatic patients with severe aortic stenosis (AS) is well established (2). Conventionally, severe AS has been defined as a valve area of $<1 \mathrm{~cm}^{2}$ with a mean gradient of $>40 \mathrm{mmHg}$. Aortic valve replacement is recommended in symptomatic patients with severe AS (3).

Assessment of the severity of AS and subsequent therapeutic decisions may be challenging, particularly in patients with low trans-valvar gradients. Severe AS with lowflow and low gradient is well described in patients with impaired left ventricular function and carries a poor prognosis when treated medically (4). Recently, a sub-group of patients with low-flow, low-gradient severe AS with preserved left ventricular ejection fraction (LVEF) has been identified. These patients have discrepant Doppler findings with a mean gradient $<40 \mathrm{mmHg}$ despite an aortic valve area $<1 \mathrm{~cm}^{2}$ and preserved LVEF (5). Several investigators have identified that these patients have a poor prognosis $(5,6,7)$ although others have found a less malignant outcome akin to moderate aortic stenosis $(8,9,10)$. Classification of AS according to valve gradient (above and below 40mmHg) and flow (above and below $35 \mathrm{mls} / \mathrm{m}^{2}$ ) may help inform outcome and therapeutic choice $(11,12)$.

The severity of aortic valve calcification (AVC), measured by ECG-gated computed tomography (CT), is a marker of valve pathology that correlates with the haemodynamic severity of AS and aortic valve area both in normal and low flow states $(13,14,15,16,17)$ and with an adverse prognosis (15). Given the conflicting data regarding the outcome of patients with different sub-types of $A S$, we investigated whether AVC might provide pathophysiological insights into patients with severe AS stratified by gradient and flow patterns. 


\section{METHODS}

\section{PATIENT COHORT}

One hundred and eighty-one consecutive patients with severe AS who were referred for consideration of trans-catheter aortic valve implantation (TAVI) and had an ECG-gated CT and trans-thoracic echocardiogram (TTE) within one month of each other were included. Severe AS was defined as a valve area of $<1 \mathrm{~cm}^{2}$ on TTE. Demographics and medical history were collected during clinical consultation. The height and weight of each patient was measured to calculate the body surface area. The blood pressure at the time of examination was recorded using an automated sphygmomanometer. Patients with bicuspid aortic valve, previous endocarditis or other moderate or severe native valve disease were excluded. The study was approved by the institutional research board and complies with the Declaration of Helsinki.

\section{ECHOCARDIOGRAPHY}

A comprehensive two dimensional echocardiogram was performed using commercially available ultrasound machines (Vivid-7 or 9, GE Healthcare, Milwaukee, WI and IE33, Phillips Healthcare, Andover, MA). Left ventricular wall thickness and diameter were measured in the parasternal long axis view. Left ventricular volumes and ejection fraction were measured and calculated using Simpsons's Biplane method in the apical four and two chamber views (18). Left ventricular outflow tract diameter was measured from the parasternal long axis view at early systole. Left ventricular outflow tract velocity time integral was measured using pulse wave Doppler in the apical 5 chamber view by placing the sample volume below the aortic valve parallel to blood flow. The highest peak trans-aortic velocity (Vmax) was measured using continuous wave Doppler from multiple windows. The aortic valve effective orifice area was 
calculated using the continuity equation. Stroke volume was calculated as left ventricular outflow tract (LVOT) cross sectional area multiplied by LVOT velocity time integral (19). Flow rate was calculated by indexed stroke volume divided by ejection time. Left ventricular mass was calculated by the Devereux formula. Relative wall thickness was calculated as 2 multiplied by posterior wall thickness divided by left ventricular end diastolic diameter. Patients were classified into normal, concentric remodelling, concentric hypertrophy and eccentric hypertrophy using relative wall thickness and indexed left ventricular mass according to guidelines (18). Patients were classified into four groups according to flow and gradient patterns: High gradient normal flow $\left(H G_{N F}\right)$, high gradient low flow $\left(H G_{L F}\right)$, low gradient normal flow (LG $\left.G_{N F}\right)$ and low gradient low flow $\left(\mathrm{LG}_{\mathrm{LF}}\right)$. Low flow was defined as trans-valvar flow $<35 \mathrm{ml} / \mathrm{m}^{2}$. Low gradient was defined as mean aortic gradient $<40 \mathrm{mmHg}$. Valvulo-arterial impedance was calculated by addition of the systolic arterial pressure to the mean transvalvular aortic pressure gradient divided by indexed stroke volume (5).

\section{CARDiac COMPUTED TOMOgRaphy}

Each patient underwent cardiac computed tomography using Toshiba Aquilion 64-slice CT scanner (Toshiba Medical Systems, Europe ). Scans were performed using prospective ECG-gating with $120 \mathrm{kVp}$ and 300-600 mAs. Each scan acquired contiguous $3 \mathrm{~mm}$ thick transverse slices images as per standard protocol. AVC was measured on non-contrast enhanced images using the Agatston Scoring system using commercially available software (Vital Images, Minnesota, USA). Numbers are given as Agatston units (AU). 
StATISTICS

Data were expressed as median and interquartile range or number and percentage. The Chi squared test was used to compare categorical variables. Where more than two groups were compared, normally distributed continuous variables were compared using the one-way analysis of variance (ANOVA) test and non-normally distributed continuous variables using the Kruskal Wallis $\mathrm{h}$ test. All tests of significance were two-sided. A probability value $(p)$ of $<0.05$ was considered statistically significant. Statistical analysis was performed using StatsDirect Version 2.5.7 (StatsDirect, United Kingdom).

\section{RESULTS}

Of the 181 patients, 46 (25\%) were classified as low gradient normal flow (LGNF), $49(27 \%)$ were classified as low gradient low flow ( $\left.\mathrm{LG}_{\mathrm{LF}}\right), 30(17 \%)$ classified as high gradient low flow $\left(\mathrm{HG}_{\mathrm{LF}}\right)$ and $56(31 \%)$ classified high gradient normal flow( $\left.\mathrm{HG}_{\mathrm{NF}}\right)$.

Baseline demographics are presented in table 1 and 2. Age, body surface area and cardiovascular risk factors and co-morbidities were similar between all four groups. Aortic valve area was higher in the LG $G_{N F}$ group than either of the other three groups.

\section{AORTIC VALVE CALCIFICATION}

The severity of AVC was similar in patients with $\mathrm{HG}_{\mathrm{NF}}$ and $\mathrm{HG}_{\mathrm{LF}}$ and in patients with $L G_{N F}$ and $L G_{L F}$. However, patients with low gradients had lower AVC scores than those with high gradients regardless of flow classification (Table 2, Figure 1).

Twenty three patients with $\mathrm{LG}_{\mathrm{LF}}$ had a LVEF $<50 \%$ and 26 had an LVEF $\geq 50 \%$. AVC was significantly lower in patients with $L G_{L F}$ and preserved LVEF compared with 


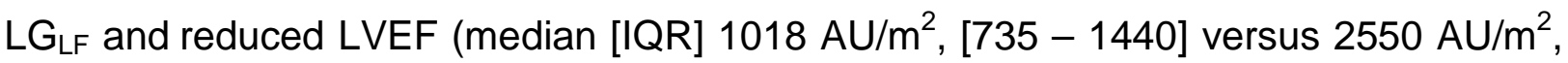
[1997-3239]; $p<0.0001)$.

Twelve patients with $L_{N F}$ had a LVEF $<50 \%$ and 34 had an LVEF $\geq 50 \%$. In patients with LG NF, AVC was similar whether LVEF was preserved or reduced (median [IQR] $1382 \mathrm{AU} / \mathrm{m}^{2}$, [1075-1610] for preserved LVEF versus $961 \mathrm{AU} / \mathrm{m}^{2}$,[640-2426] for reduced LVEF; $p=0.7)$.

\section{LEFT VENTRICULAR MASS AND PATTERNS OF LEFT VENTRICULAR HYPERTROPHY}

Left ventricular mass was increased in all groups (table 2). Figure 2 shows the different patterns of left ventricular hypertrophy identified in each group. A significantly greater proportion of patients in $\mathrm{HG}_{\mathrm{NF}}$ (71.4\%) group expressed a concentric hypertrophy pattern compared to $\operatorname{LG}_{N F}(45.7 \%, p=0.0002), L_{L F}(38.8 \%, p<0.0001)$ and $H G_{L F}(53.3 \%, p=0.01)$ groups. A significantly greater proportion of $L G_{L F}(28.6 \%)$ and $\mathrm{LG}_{\mathrm{NF}}(30.4 \%)$ expressed an eccentric hypertrophy pattern compared to the $\mathrm{HG}_{\mathrm{NF}}(8.9 \%$, $\mathrm{p}=0.0004$ and $\mathrm{p}=0.0001$ respectively) and $\mathrm{HG}_{\mathrm{LF}}(16.7 \%, \mathrm{p}=0.04$ and $\mathrm{p}=0.03$ respectively) groups. There were no significant differences in the proportion of patients with concentric remodelling between the four group $(p=0.77)$.

In $L G_{L F}$ with preserved ejection fraction concentric hypertrophy, eccentric hypertrophy, concentric remodelling and normal wall thickness were found in 10 (43.4\%),8 (35\%), 2 (9\%) and 3(13\%) patients respectively. In LG $\mathrm{LF}_{\mathrm{LF}}$ with reduced ejection fraction concentric hypertrophy, eccentric hypertrophy, concentric remodelling and normal thickness were found in 10 (38\%),6 (23\%), $8(31 \%)$ and 2(8\%) patients respectively.

In $L G_{N F}$ with preserved ejection fraction concentric hypertrophy, eccentric hypertrophy, concentric remodelling and normal wall thickness were found in 16 
(47\%),10 (29\%), $5(15 \%)$ and 3(9\%) patients respectively. In LG $_{N F}$ with reduced ejection fraction concentric hypertrophy, eccentric hypertrophy, concentric remodelling and normal thickness were found in 5 (42\%),4 (33\%), 1 (8\%) and 2(17\%) patients respectively.

VALVULO-ARTERIAL IMPEDANCE

Median valvulo-arterial impedance in the $L G_{N F}, L_{L F}, H G_{N F}$ and $H G_{L F}$ were $4.2 \mathrm{mmHg} / \mathrm{ml} / \mathrm{m}^{2}$ (interquartile range 3.6-4.9), $5.9 \mathrm{mmHg} / \mathrm{ml} / \mathrm{m}^{2}$ (interquartile range 4.9 7.3), $4.5 \mathrm{mmHg} / \mathrm{ml} / \mathrm{m}^{2}$ (interquartile range $3.9-5.0$ ) and $6.4 \mathrm{mmHg} / \mathrm{ml} / \mathrm{m}^{2}$ (interquartile range 5.5-7.0) respectively. $\mathrm{LG}_{\mathrm{LF}}$ had significantly higher valvulo-arterial impedance than the $L G_{N F}$ and $H G_{N F}$ groups $(p<0.0001)$ (Figure 3).

There was no significant difference in valvulo-arterial impedance between the $\mathrm{LG}_{\mathrm{LF}}$ with reduced (median $5.7 \mathrm{mmHg} / \mathrm{ml} / \mathrm{m} 2$, interquartile range $4.9-7.2$ ) and $\mathrm{LG}_{\mathrm{LF}}$ with preserved ejection fraction groups(median $6.2 \mathrm{mmHg} / \mathrm{ml} / \mathrm{m} 2$, interquartile range 4.9 7.3), $p=0.48$. There was no significant difference in valvulo-arterial impedance between the $L G_{N F}$ with reduced ejection fraction (median $4.6 \mathrm{mmHg} / \mathrm{ml} / \mathrm{m} 2$, interquartile range 3.7- 5.4) and $L G_{N F}$ with preserved ejection fraction groups (median $4.1 \mathrm{mmHg} / \mathrm{ml} / \mathrm{m} 2$, inter-quartile range 3.5-4.7), $p=0.17$

\section{DISCUSSION}

Our study demonstrates in AS patients with a valve area $<1 \mathrm{~cm}^{2}$ there is a continuum of disease. Patients with severe AS and high mean gradient $(>40 \mathrm{mmHg})$ irrespective of trans-valvular flow have a heavily calcified valve with high aortic valve calcification score. In contrast, patients with a valve area $<1 \mathrm{~cm}^{2}$ and a low mean gradient $(<40 \mathrm{mmHg})$ have significantly less aortic valve calcification. Those with $\mathrm{LG}_{\mathrm{LF}}$ 
and preserved ejection fraction have lower AVC than patients with high gradients suggesting that this may represent a less severe degree of AS.

Calculation of trans-valvar aortic pressure difference is flow dependent (20). Flow and stroke volume can be reduced or normal in patients with both normal and reduced ejection fraction. Therefore in patients with severe aortic stenosis there can be a range of different flow and gradient patterns. Whilst in patients with concordant data (valve area $<1 \mathrm{~cm}$, mean gradient $\geq 40 \mathrm{mmHg}$ and $V \max >4 \mathrm{~m} / \mathrm{s}$ ) clinicians can be certain about the diagnosis, in patients with discordant data (valve area $<1 \mathrm{~cm}^{2}$ but mean gradient $<40 \mathrm{mmHg}$ ) there may be diagnostic doubt about the severity of the valve lesion and hence benefit of aortic valve intervention.

Aortic valve calcification has previously shown to have a good correlation with excised aortic valve weight and specificity for severe AS in both normal and low flow states $(15,16)$. In patients with reduced LVEF, low dose dobutamine stress echocardiography is helpful for identification of contractile reserve for risk stratification and determining whether the AS is truly severe or not $(4,21)$. In patients without contractile reserve it may not be possible to differentiate between severe and moderate AS using DSE. In this setting, valve calcium scores may be helpful to decide upon disease severity. Previous data have suggested a calcium score of 1651 arbitrary units reliably identifies severe stenosis (16). Gender differences may exist and an indexed calcium score of $637 \mathrm{AU} / \mathrm{m}^{2}$ in women and $1,067 \mathrm{AU} / \mathrm{m}^{2}$ in men provided the best sensitivity and specificity for severe aortic stenosis (17). Our study confirms this data with low flow, low gradient severe AS patients with reduced ejection fraction having high aortic valve calcification.

In patients with $\mathrm{LG}_{\mathrm{LF}}$ but preserved ejection fraction, Hachicha and colleagues first suggested these patients have a poor outcome and hence this flow/gradient 
pattern may represent a more severe form of AS (5). However other groups have challenged this view $(8,10)$. Recently, Tribouilloy et al $(8)$ suggested the outcome of this group is more favourable than previously reported. In our analysis, these patients had significantly lower aortic valve calcification than those patients with high gradients or patients with $L G_{L F}$ and reduced ejection fraction. Therefore, we propose this group has less critical valve obstruction than other sub-types of AS.

In our study, global afterload was significantly higher for $L G_{L F}$ with preserved ejection fraction than sub-types of AS with normal flow. Eleid et al (22) compared patients with $L G_{L F}$ and preserved ejection fraction to patients with high gradients using invasive measures of afterload. They found $L G_{L F}$ with preserved ejection fraction patients had a higher effective arterial elastance and systemic vascular resistance and lower total arterial compliance than patients with high gradients. This suggests abnormal vascular/arterial load in addition to valve stenosis is an important component of this entity. Therefore, the reason for the reported adverse outcome of this group may be due to a combination of the adaptive response of the ventricle to high afterload in combination with valve obstruction rather than AS alone.

LG ${ }_{N F}$ patients have lower AVC than patients with high gradients. They also had higher aortic valve areas than any of the other groups. This suggests the degree of aortic stenosis is not as severe as the other groups. This is supported by the findings of Eleid et al (12) who showed the prognosis of LGNF with preserved ejection fraction was more favourable than other sub-types of aortic stenosis. Furthermore, Kamperidis et al (23) showed echocardiography frequently under-estimated LVOT area compared to CT derived LVOT area. Substitution of CT derived LVOT area into the aortic valve continuity equation resulted in $52 \%$ of $L G_{N F}$ patients in their study being classified a moderate AS. Our data is supported by the recent findings of Maes et al (9) who found 
there was progression in aortic trans-valvar gradients over time in the majority of patients they termed "paradoxical low gradient severe aortic stenosis". Nearly a half of these patients eventually developed high gradient severe aortic stenosis. Therefore we propose patients with low gradient severe aortic stenosis and preserved ejection fraction with either low or normal flow may represent an earlier stage of the disease process.

The main limitation of this study is the sample size in each sub-group. Therefore sub-group analysis for gender differences could not be evaluated. Furthermore classification of patients was based on echocardiographic measurement of the LVOT diameter which relies on geometric assumptions of the LVOT area. Dobutamine stress echocardiography was not performed in all patients with $L_{\mathrm{LF}}$ with reduced ejection fraction and therefore some patients may have pseudo-severe AS rather than severe AS.

\section{CONCLUSION}

Distinct pathological and physiological differences exist between patients with AS and aortic valve area $<1 \mathrm{~cm}^{2}$ when stratified according to patterns of flow and gradient. $L G_{L F}$ with preserved ejection fraction is associated with less AVC, more heterogeneous LV geometry and higher global afterload than high gradient patterns. This flow and gradient pattern may identify patients who in fact have less severe AS in association with an adaptive ventricular response to high afterload.

CONFLICTS OF INTEREST: None

FUNDING: None 


\section{AUTHOR CONTRIBUTION:}

$\mathrm{SB}, \mathrm{MA}, \mathrm{TM}$ and SR contributed to the design of the study, data collection and analysis, drafting of the manuscript and approved the final manuscript. TK, MD, JC, AB contributed to data analysis, manuscript revision and approved the final manuscript. 


\section{REFERENCES}

1. Nkomo VT, Gardin JM, Skelton TN, Gottdiener JS, Scott CG, Enriquez-Sarano M. Burden of valvular heart diseases: a population-based study. Lancet 2006;368:1005-1011.

2. Ross J, Braunwald E. Aortic Stenosis. Circulation 1968;36:381-386.

3. Vahanian A, Alfieri O, Andreotti F, Antunes MJ, Barón-Esquivia G, Baumgartner H, et al. Guidelines on the management of valvular heart disease (version 2012): The Joint Task Force on the Management of Valvular Heart Disease of the European Society of Cardiology (ESC) and the European Association for Cardio-Thoracic Surgery (EACTS). Eur Heart J 2012;33:2451-1496.

4. Monin JL, Quéré JP, Monchi M, Petit H, Baleynaud S, Chauvel C, et al. Lowgradient aortic stenosis: operative risk stratification and predictors for long-term outcome: a multi-center study using dobutamine stress hemodynamics. Circulation 2003;108:319-324.

5. Hachicha Z, Dumesnil JG, Bogaty P, Pibarot P. Paradoxical low-flow, low-gradient severe aortic stenosis despite preserved ejection fraction is associated with higher afterload and reduced survival. Circulation 2007;115:2856-2864.

6. Clavel MA, Dumesnil JG, Capoulade R, Mathieu P, Sénéchal M, Pibarot P. Outcome of patients with aortic stenosis, small valve area, and low-flow, lowgradient despite preserved left ventricular ejection fraction. J Am Coll Cardiol 2012;60:1259-1267.

7. Mehrotra P, Jansen K, Flynn AW, Tan TC, Elmariah S, Picard MH, et al. Differential left ventricular remodelling and longitudinal function distinguishes low flow from normal-flow preserved ejection fraction low-gradient severe aortic stenosis. Eur Heart J 2013 ;34:1906-1914. 
8. Tribouilloy C, Rusinaru D, Maréchaux S, Castel AL, Debry N, Maizel J, et al. Lowgradient, low-flow severe aortic stenosis with preserved left ventricular ejection fraction: characteristics, outcome, and implications for surgery. J Am Coll Cardiol 2015;65:55-66.

9. Maes F, Boulif J, Piérard S, de Meester C, Melchior J, Gerber B, et al. Natural history of paradoxical low-gradient severe aortic stenosis. Circ Cardiovasc Imaging 2014;7:714-722.

10. Jander N, Minners J, Holme I, Gerdts E, Boman K, Brudi P, et al. Outcome of patients with low-gradient "severe" aortic stenosis and preserved ejection fraction. Circulation 2011;123:887-895.

11. Lancellotti P, Magne J, Donal E, Davin L, O'Connor K, Rosca M, et al. Clinical outcome in asymptomatic severe aortic stenosis: insights from the new proposed aortic stenosis grading classification. J Am Coll Cardiol 2012;59:235-243.

12. Eleid MF, Sorajja P, Michelena HI, Malouf JF, Scott CG, Pellikka PA. Flow-gradient patterns in severe aortic stenosis with preserved ejection fraction: clinical characteristics and predictors of survival. Circulation 2013;128:1781-1789.

13. Freeman RV, Otto CM. Spectrum of calcific aortic valve disease: pathogenesis, disease progression, and treatment strategies. Circulation 2005;111:3316-3326.

14. Rosenhek R, Binder T, Porenta G, Lang I, Christ G, Schemper M, et al. Predictors of outcome in severe, asymptomatic aortic stenosis. N Engl J Med 2000;343:611617.

15. Messika-Zeitoun D, Aubry MC, Detaint D, Bielak LF, Peyser PA, Sheedy PF, et al. Evaluation and clinical implications of aortic valve calcification measured by electron-beam computed tomography. Circulation 2004;110:356-362.

16. Cueff C, Serfaty JM, Cimadevilla C, Laissy JP, Himbert D, Tubach F, et al. Measurement of aortic valve calcification using multislice computed tomography: 
correlation with haemodynamic severity of aortic stenosis and clinical implication for patients with low ejection fraction. Heart 2011;97:721-726.

17. Clavel MA, Messika-Zeitoun D, Pibarot P, Aggarwal SR, Malouf J, Araoz PA, et al. The complex nature of discordant severe calcified aortic valve disease grading: new insights from combined Doppler echocardiographic and computed tomographic study. J Am Coll Cardiol 2013;62:2329-2338.

18. Lang RM, Badano LP, Mor-Avi V, Afilalo J, Armstrong A, Ernande L, et al. Recommendations for cardiac chamber quantification by echocardiography in adults: an update from the american society of echocardiography and the European association of cardiovascular imaging. Eur Heart J Cardiovasc Imaging 2015;3:233271.

19. Baumgartner H, Hung J, Bermejo J, Chambers JB, Evangelista A, Griffin BP, et al. Echocardiographic assessment of valve stenosis: EAE/ASE recommendations for clinical practice. Eur J Echocardiogr 2009;1:1-25.

20. Voelker W, Reul H, Nienhaus G, Stelzer T, Schmitz B, Steegers A, et al. Comparison of valvular resistance, stroke work loss, and Gorlin valve area for quantification of aortic stenosis. An in vitro study in a pulsatile aortic flow model. Circulation 1995;91:1196-1204.

21. deFilippi CR, Willett DL, Brickner ME, Appleton CP, Yancy CW, Eichhorn EJ, et al. Usefulness of dobutamine echocardiography in distinguishing severe from nonsevere valvular aortic stenosis in patients with depressed left ventricular function and low transvalvular gradients. Am J Cardiol 1995;75:191-194.

22. Eleid MF, Nishimura RA, Borlaug BA, Sorajja P. Invasive measures of afterload in low gradient severe aortic stenosis with preserved ejection fraction. Circ Heart Fail 2013;6:703-710. 
23. Kamperidis V, van Rosendael PJ, Katsanos S, van der Kley F, Regeer M, Al Amri I, Sianos G, Marsan NA, Delgado V, Bax JJ. Low gradient severe aortic stenosis with preserved ejection fraction: reclassification of severity by fusion of Doppler and computed tomographic data. Eur Heart J 2015;36:2087-2096. 


\section{FIGURE LEGENDS}

Figure 1. Box and Whisker Plot. Aortic valve calcification score according to valve gradient and flow patterns.

Figure 2. Patterns of left ventricular hypertrophy according to valve gradient and flow.

Figure 3. Valvulo-arterial impedance stratified according to valve gradient and flow patterns. 